\title{
RANCANG BANGUN SISTEM INFORMASI PEMBAYARAN IURAN WARGA RT 05 RW 002 BERBASIS JAVA
}

\author{
Wahyu Arif Rahman', Lusi Ariyani \\ Program Studi Teknik Informatika, Fakultas Teknik dan Ilmu Komputer, \\ Universitas Indraprasta PGRI \\ Jalan Raya Tengah No 80, Kelurahan Gedong, Pasar Rebo, Jakarta Timur \\ croooscream@gmail.com ${ }^{1}$, lusiariyani0312@gmail.com²
}

\begin{abstract}
Abstrak
Setiap pemerintahan daerah khususnya rukun tetangga yang lebih sering dijumpai, perlu meningkatkan kualitas sumber daya manusia terutama dalam perkembangan teknologi informasi saat ini. Administrasi yang baik tentu tidak lepas dari data - data yang banyak dan dapat berubah sewaktu-waktu, dalam hal ini adalah data warga berikut dengan pembayaran iuran warga. Pada kajian ini, rancang bangun sistem informasi pembayaran iuran warga RT 05 RW 002 berbasis Java Netbeans dan MySQL dapat relevan dengan sistem yang bertujuan untuk mengatasi masalah pembayaran iuran warga. Hasil dari penelitian ini adalah sistem informasi pembayaran iuran warga yang dapat membantu petugas dan pengurus RT dalam mengelola data warga dan pembayaran iuran warga secara lebih baik dan tentunya dapat mempermudah perhitungan pembayaran secara akurat.
\end{abstract}

Kata Kunci: Sistem Informasi, Pembayaran, Iuran, Warga, Java, MySQL

\begin{abstract}
Every local government, especially RT that are more commonly encountered, needs to improve the quality of human resources, especially in the development of information technology today. Good administration certainly cannot be separated from the data - data that is a lot and can change at any time, in this case is the following citizen data with the payment of citizen dues. In this study, the design of the RT 05 RW 002 citizen contribution payment information system based on Java Netbeans and MySQL can be relevant to the system that aims to overcome the problem of payment of citizen dues. The result of this study is a citizen contribution payment information system that can help RT officers and administrators in managing citizen data and citizen contribution payments better and of course can facilitate accurate payment calculation.
\end{abstract}

Keyword: Information System, Payment, Fees, Citizen, Java, MySQL.

\section{PENDAHULUAN}

Perkembangan teknologi dan perkembangan ilmu pengetahuan memicu banyak kalangan untuk mencari alternatif pemecahan masalah dibidang teknologi sistem informasi (Lahay \& Sulaeman, 2019). Sebagai contohnya adalah pemerintah daerah yang saat ini menggunakan sistem informasi untuk mengefektifkan sistem yang sedang berjalan. Saat ini pemerintah daerah khususnya pada tingkat rukun tetangga belum menggunakan teknologi informasi sebagai pendukung operasionalnya baik teknis maupun non teknis salah satunya RT 005 RW 02 Kelurahan Cibubur. Jumlah warga yang banyak dikelompokkan dengan istilah Rukun Tetangga (RT) (Wiyandari \& Pohan, 2019) hal ini menjadi tantangan bagi rukun tetangga agar tetap bisa mengikuti era yang modern saat ini. Namun memang banyak pemerintahan daerah yang masih kurang paham bagaimana cara membangun sistem informasi pendukung tersebut. Dalam rukun tetangga hal yang akan lebih sering dijumpai adalah kegiatan iuran bulanan, iuran sampah dan iuran keamanan. Banyak rukun tetangga hanya menuliskan daftar iuran warga hanya menggunakan catatan tulis pada sebuah buku atau pada lembar kertas form iuran saja. Sehingga sering terjadi kesalahan penginputan nominal pembayaran (I Made Dwi Putra Asana, Putra, \& Ketut Jaya Atmajaya, 2020). Sehingga tidak jarang ada kekeliruan akan data iuran dikarenakan ada data yang hilang atau lupa tercatat. Hal ini menyebabkan sistem iuran warga menjadi kurang efektif. Selama ini proses data iuran dan pengolahan data warga pada RT 005 RW 02 Kelurahan Cibubur masih bersifat manual 
sehingga banyak kendala dalam pengolahan data iuran warga. Pada RT 005 RW 02 Kelurahan Cibubur media penyimpanan masih berupa arsip-arsip yang besar kemungkinan rusak atau hilang, sehingga menyulitkan dalam mengetahui perkembangan warga. Hal ini juga menyebabkan pengolahan data warga, perhitungan dan pembuatan laporan pun tidak bisa dilakukan dengan cepat. Untuk itu diperlukan sebuah perancangan sistem agar semua kegiatan berjalan dengan baik. Dalam mengatasi permasalahan (I M D P Asana, Putra, \& Atmaja, 2020) maka teknologi yang tepat adalah sistem komputerisasi dengan menggunakan sistem komputerisasi semua aktivitas yang bersifat manual diganti dengan menggunakan teknologi yang tepat sesuai kebutuhan. Komputerisasi sistem iuran warga pun sangat diperlukan sehingga akan memperkecil kesalahan serta dapat memberikan informasi dengan cepat, efektif dan efisien.

\section{PENELITIAN RELEVAN}

Penelitian oleh Mukhtar (2017). Sistem Informasi Iuran Keamanan Warga RW.04 Kel. Tampan Kec. Payung Sekaki Berbasis Web. Dengan di terapkannya Sistem Informasi Pengolahan Data Iuran Keamanan Warga Kel. Tampan Kec. Payung Sekaki yang Berbasis Web ini, dapat memberikan kemudahan dan memperlancar pengolahan data iuran keamanan yang dapat diproses dengan cepat, baik dari segi penginputan data, pencarian data maupun dalam proses pelaporan data (Mukhtar, 2017).

Penelitian oleh Endah Pamularsih (2020). Perancangan Sistem Pengolahan Data Iuran Sampah Dan Penggajian Petugas Di Kampung Baru Berbasis Java. Penelitian ini bertujuan untuk memberikan kemudahan dalam pengolahan data iuran sampah dan penggajian petugas. Pengolahan data menjadi lebih efisien, efektif dan keakuratan data menjadi lebih terjamin (Pamularsih, 2020).

\section{METODE PENELITIAN}

Metode penelitian yang digunakan metode grounded research, metode observasi (pengamatan) dan metode pengumpulan data untuk mendukung penelitian ini sebagai berikut :

\section{a. Observasi}

Peneliti melakukan pengamatan langsung dengan sistem yang sedang berjalan, dengan pencatatan, dan pengumpulan data-data yang dilakukan pada RT 05 RW 002 Kelurahan Cibubur, Jakarta Timur, DKI Jakarta.

\section{b. Wawancara}

Penelitian melakukan wawancara secara langsung kepada Bapak Nardi Wirnano selaku Kepala RT 05/002 mengenai pembayaran iuran warga. Hasil wawancara merupakan kelengkapan data yang tujuannya sebagai pertimbangan dalam mengambil kesimpulan penelitian.

\section{c. Studi Pustaka}

Pengumpulan data dan informasi dari kutipan-kutipan berbagai buku, peraturan perundangundangan, serta hasil laporan dan bahan lainnya yang berkaitan dengan penelitian ini.

\section{HASIL DAN PEMBAHASAN}

Aturan bisnis sistem yang diusulkan dalam sistem informasi pembayaran iuran warga RT 05 RW 002 adalah sebagai berikut :

1. Data Warga

Petugas memasukan data warga dan menyimpan data tersebut ke dalam sistem informasi, yang kemudian petugas mengelola data untuk kepentingan adminstrasi warga.

2. Data Petugas Petugas memasukan semua data petugas dan menyimpan data tersebut ke dalam sistem informasi, yang kemudian petugas mengelola data untuk kepentingan adminstrasi.

3. Iuran Warga Petugas memasukan pembayaran iuran yang sudah dibayarkan oleh warga dan menyimpan data tersebut ke dalam sistem informasi, petugas mengelola data yang kemudian diteruskan ke bagian pengurus untuk kepentingan laporan pembayaran iuran. 
4. Bantuan Warga

Petugas memasukan bantuan warga untuk warga yang membutuhkan bantuan dana dan menyimpan data tersebut ke dalam sistem informasi, petugas mengelola data yang kemudian diteruskan ke bagian pengurus untuk kepentingan laporan bantuan warga.

5. Laporan

Bagian pengurus mencetak laporan data warga, laporan data ketua, laporan data petugas, laporan pembayaran iuran dan laporan bantuan warga.

DFD adalah suatu network yang menggambarkan suatu sistem komputerisasi, manualisasi, atau gabungan dari keduanya, yang penggambarnya disusun dalam bentuk kumpulan komponen sistem yang saling berhubungan sesuai dengan aturan mainnya (Sutabri, 2012). Berikut adalah rancangan diagram alir data :

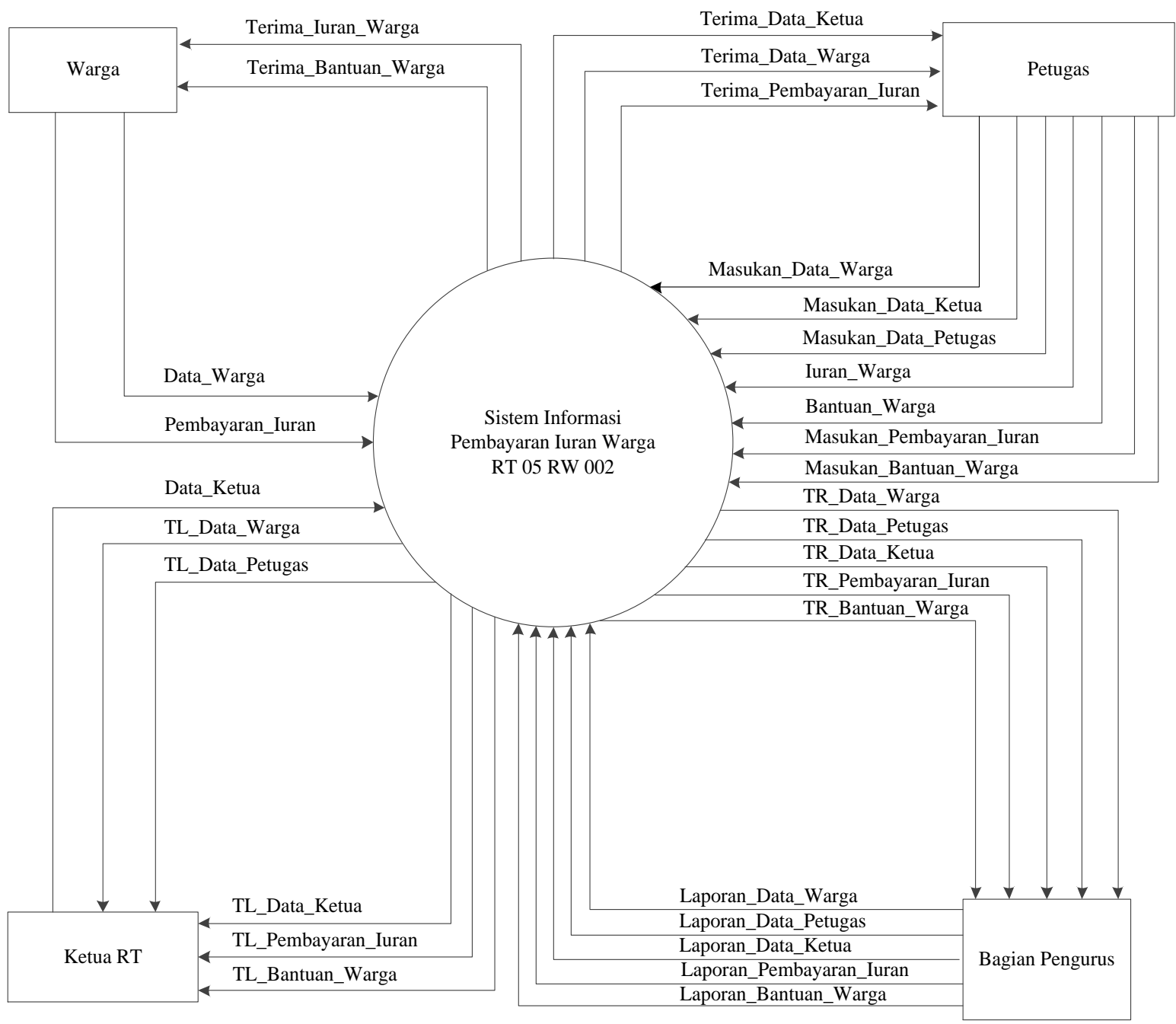

Gambar 1. Diagram Alir Data (DAD)

Dalam perancangan sistem informasi pembayaran iuran warga RT 05 RW 002 menggunakan penyimpanan basis data. Database adalah suatu kumpulan atau susunan data operasional lengkap dari suatu organisasi yang diorganisir atau dikelola dan disimpan secara terintegritasi dengan menggunakan metode tertentu menggunakan komputer sehingga mampu menyediakan informasi 
yang optimal yang diperlukan pemakainya (Yutanto, Ilham, Salma, \& Effendi, 2019). MySQL adalah database open source paling populer di dunia (Arya, 2018). ERD (Entity Relationship Diagram) adalah suatu model jaringan yang menggunakan susunan data yang disimpan dalam sistem secara abstrak (Kurniawan, Enggari, \& Rani, 2019)(Ladjamudin, 2013).

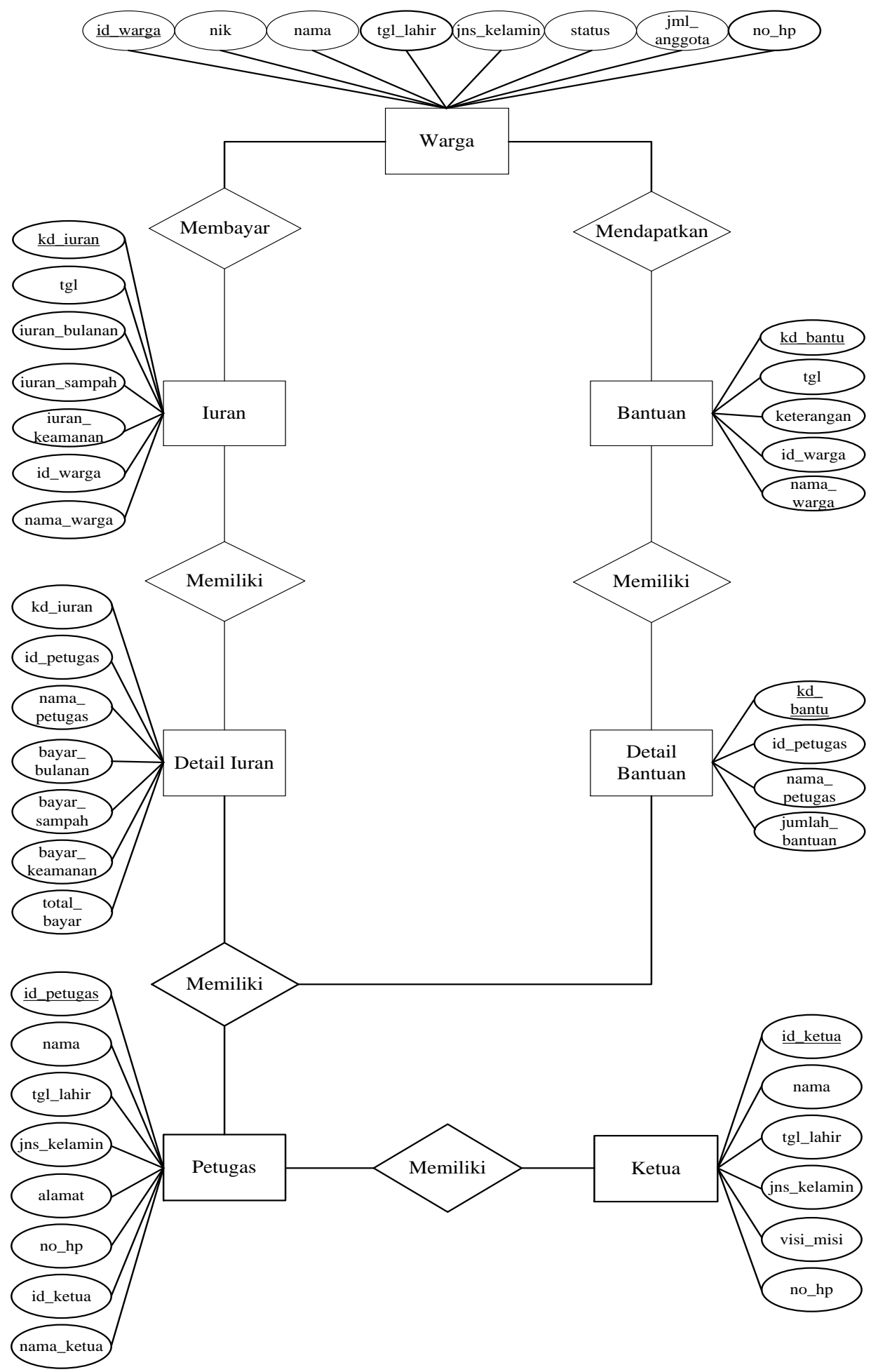

Gambar 2. Entity Relationship Diagram 
Tampilan layar sistem informasi penggajian guru :

1. Form Iuran Warga

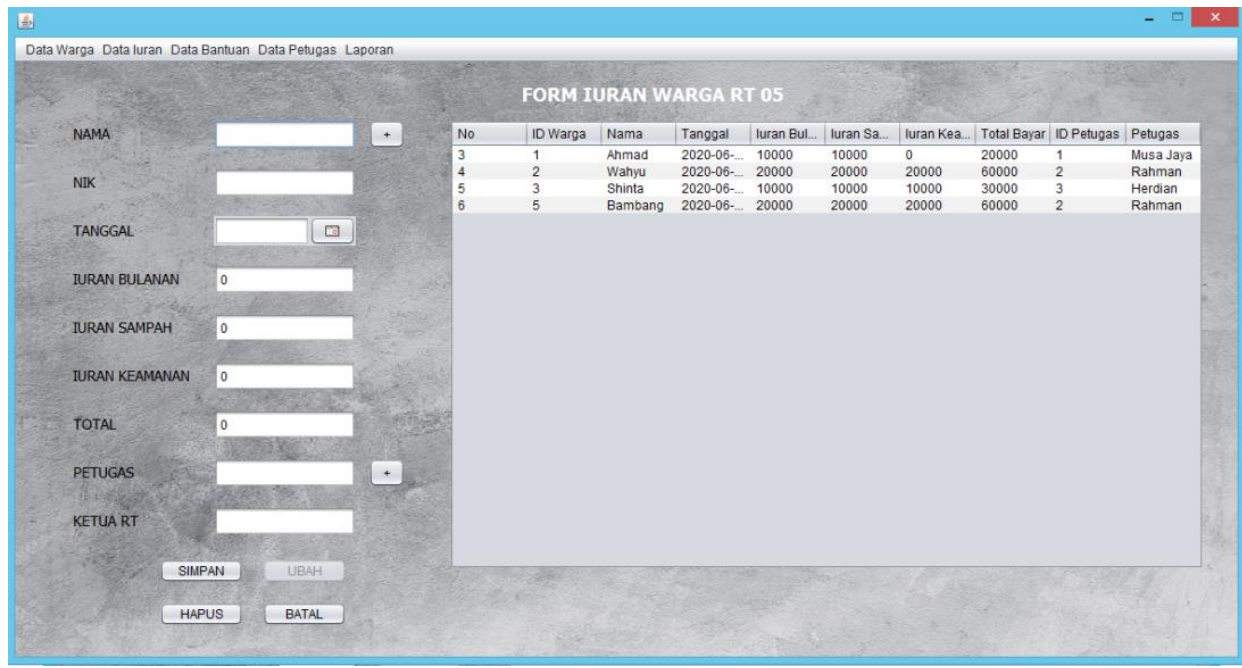

2. Form Bantuan Warga

Gambar 3. Form Iuran Warga

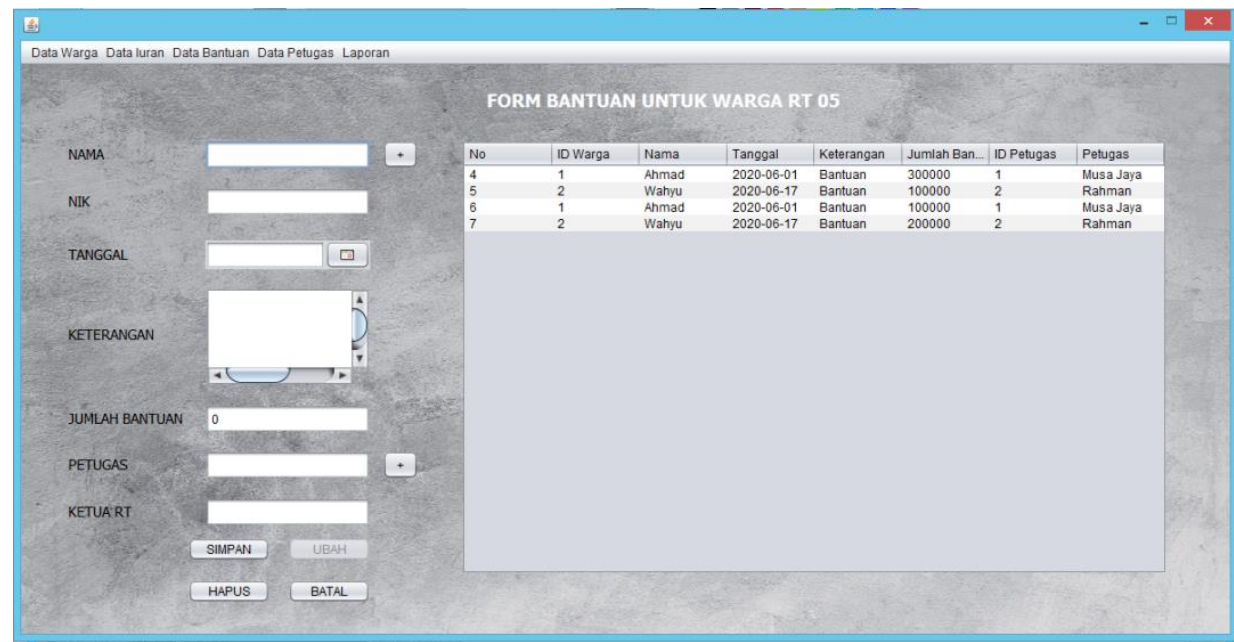

Gambar 4. Form Bantuan Warga

\section{Form Laporan Iuran Warga}

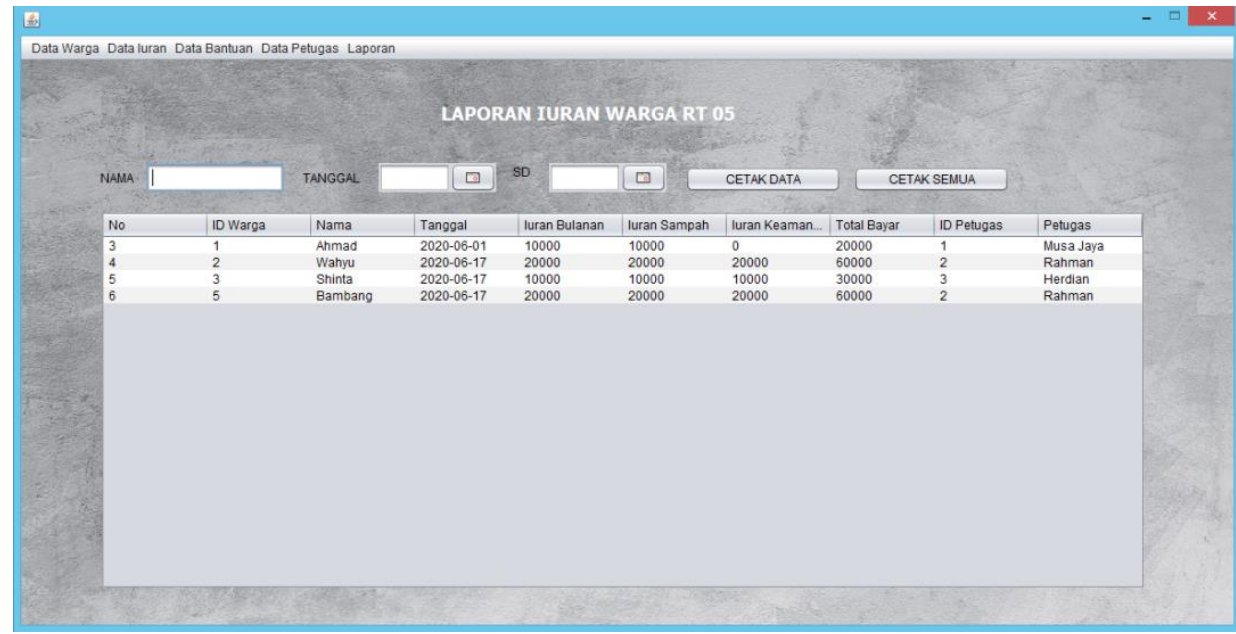

Gambar 5. Form Laporan Iuran Warga 
4. Laporan Iuran Warga

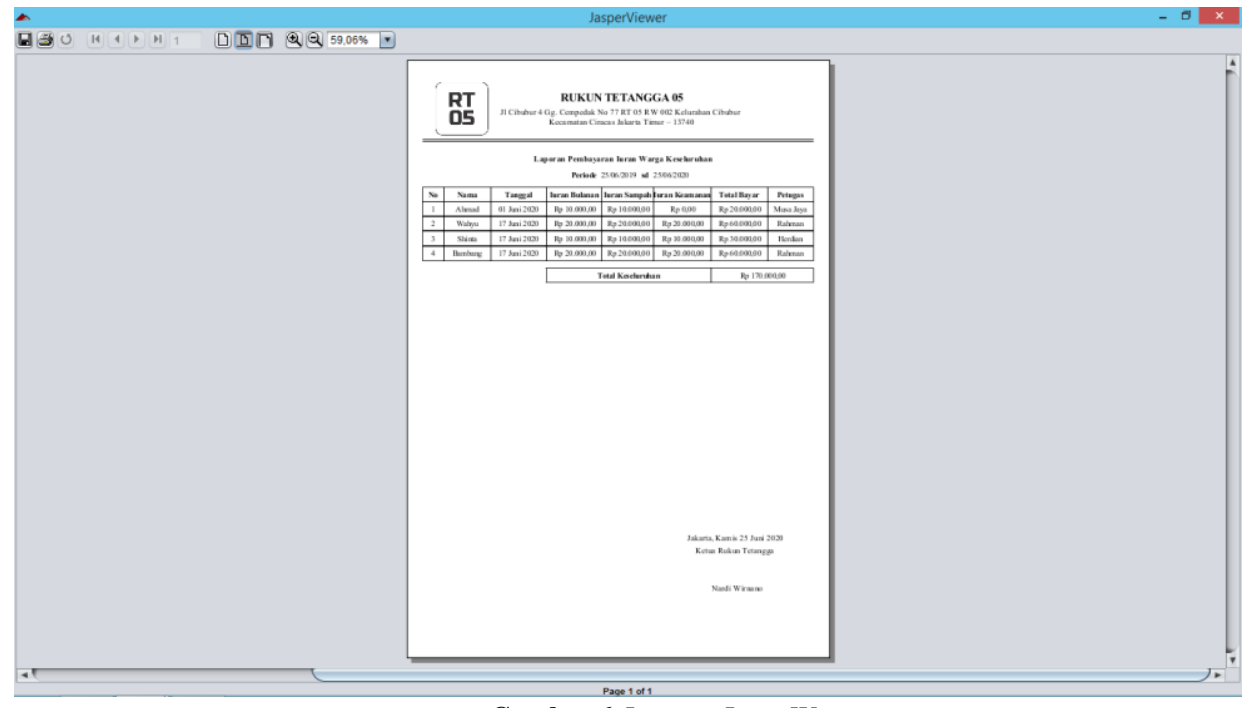

Gambar 6. Laporan Iuran Warga

\section{SIMPULAN}

Peranan teknologi informasi memiliki pengaruh yang sangat besar pada kehidupan manusia. Hal ini terjadi karena dengan teknologi informasi manusia dapat membuat apa saja menjadi lebih mudah dan efisien. Dengan dibuatnya aplikasi pembayaran iuran warga berbasis komputer di RT 005 RW 02 Kelurahan Cibubur, Jakarta Timur, DKI Jakarta, memudahkan dalam proses menganalisa data pembayaran dan laporan keuangan serta memudahkan dalam proses input data pembayaran begitu pula terhadap keamanan data-data warga menjadi terjaga (Pamularsih, 2020) kegiatan pembayaran yang berhubungan dengan pengolahan data pada aplikasi ini serta pemakai sistem dapat bekerja lebih efesien, mudah dan cepat. Sistem informs ini diharapkan dapat mempermudah kegiatan pengolahan data atau pekerjaan seluruh anggota pengurus di RT 05 RW 02 Kelurahan Cibubur, Jakarta Timur, DKI Jakarta.

\section{DAFTAR PUSTAKA}

Arya, N. (2018). Pembuatan Aplikasi Kegiatan Warga Pada RT 06 RW 06 Kelurahan Airlangga Berbasis Android. Jurnal Infra Petra.

Asana, I M D P, Putra, P. S. U., \& Atmaja, K. J. (2020). Penerapan Teknologi Informasi Berbasis Mobile Dalam Manajemen Iuran Warga di SekretariatMahaSemaya Ki Mantri Tutuan Gunaksa. 3(1), 40-45.

Asana, I Made Dwi Putra, Putra, P. S. U., \& Ketut Jaya Atmajaya. (2020). Penerapan Sistem Informasi Data Iuran di Sekretariat Warga Tutuan Gunaksa. Jurnal Anadara Pengabdian Kepada Masyarakat, 2(1), 12-17. Retrieved from http://jurnal.una.ac.id/index.php/anadara/issue/view/115

Kurniawan, A., Enggari, S., \& Rani, L. N. (2019). Perancangan Sistem Pengolahan Laporan Data Gaji Guru Basiskan Desktop Pada Sekolah Sdn 06 Guguk Sarai Kab. Solok Dengan Menerapkan Bahasa Pemrograman Java Dan Database Mysql. UPI YPTK Jurnal EKOBISTEK, 1(1), 1-18.

Ladjamudin, A.-B. Bin. (2013). Analisis dan Desain Sistem Informasi. Yogyakarta: Graha Ilmu.

Lahay, D., \& Sulaeman, S. (2019). Perancangan Sistem Informasi Pengelolaan Tagihan Iuran Pemasangan Jaringan Pada Pt. Molindo Media Persada Berbasis Android. 2019(November), 44-49.

Mukhtar. (2017). Sistem Informasi Iuran Keamanan Warga Rw.04 Kel. Tampan Kec. Payung Sekaki Berbasis Web. Intra Tech, 2(Vol 1 No 2 (2017): Jurnal Intra Tech), 10-17.

Pamularsih, E. (2020). Perancangan Sistem Pengolahan Data Iuran Sampah. 367-374.

Sutabri, T. (2012). Analisis Sistem Informasi. Yogyakarta: Andi Yogyakarta.

Wiyandari, S., \& Pohan, N. (2019). JUSTI - Jurnal Sains dan Teknologi Informasi. Jurnal Sains Dan Teknologi Informatika, I(I), 1-5.

Yutanto, H., Ilham, R., Salma, K. R., \& Effendi, Y. (2019). Pengembangan Sistem Informasi Pada Local EGovervenance Untuk Peningkatan Kinerja Pelayanan Warga. Jurnal Sistem Informasi Bisnis, 9(2), 22. https://doi.org/10.21456/vol9iss2pp220-227 